\title{
APLICAÇÃO DO MÉTODO DOS ELEMENTOS FINITOS NA DETERMINAÇÃO DA CARGA LIMITE DE ELEMENTOS ESTRUTURAIS DE ALTO DESEMPENHO
}

\author{
L. A. S. Souza ${ }^{1}$, S. T. M. Souza ${ }^{2}$ \\ ${ }^{1}$ Universidade Estadual de Londrina, Depto. de Estruturas, Londrina, Pr. (lasouzza@uel.br) \\ ${ }^{2}$ Universidade Tecnológica Federal do Paraná, Londrina, Pr. (suelisouza@utfpr.edu.br)
}

Resumo. $O$ uso de concreto de alto desempenho vem sendo intensificado cada vez mais em nossas edificações devido às suas características mecânicas e de durabilidade. Quando aplicado aos elementos estruturais merece investigação acerca das suas propriedades mecânicas. Neste trabalho são mostradas algumas aplicações do método dos elementos finitos na determinação da carga última de elementos estruturais (vigas e pilares), fabricados com este material. Muitos dos insucessos das respostas da simulação computacional estão na má representação das características físicas deste material e na escolha do critério de ruptura. Somente o conhecimento do módulo de elasticidade e tensões de ruptura têm-se mostrado insuficiente para a obtenção de uma boa resposta computacional. Melhores resultados podem ser obtidos através de um programa computacional desenvolvido para este fim levando-se em conta a curva tensão-deformação destes materiais (aço e concreto). O programa desenvolvido possibilita análises com os critérios de Von-Mises, Tresca, Mohr-Coulomb e DruckerPrager. O elemento finito utilizado é o quadrático de oito nós, para estado plano de tensão, estado plano de deformação e axissimétrico. Para a análise não linear física foram implementados os algoritmos de Newton Raphson (NR) e NR modificado. São mostradas análises de elementos estruturais submetidos tanto à compressão (pilar) quanto à flexão (viga) e os resultados são comparados com resultados experimentais obtidos por outros pesquisadores. A boa concordância entre os resultados mostra que a análise computacional em muitos casos práticos é uma ferramenta muito útil para a determinação de cargas limites de ruptura, podendo em alguns casos prescindir a análise experimental, o que reduz tempo e custo.

Palavras chaves: Elementos Finitos, Concreto de alto desempenho, Plasticidade, Critérios de Ruptura.

\section{INTRODUÇÃO}

O concreto é tipicamente um material que possui uma gama de variações relacionadas com as propriedades físicas e mecânicas. Estas variações podem ser minimizadas com um rigoroso controle tecnológico, através de ensaios experimentais e tratamentos estatísticos. $\mathrm{O}$ concreto possui uma curva tensão-deformação, dependente da velocidade e do tempo de per- 
manência do carregamento. É um material que trabalha essencialmente à compressão, pois a resistência à tração é muito baixa, evidenciando desta forma a necessidade do uso de barras de aço.

O aço apresenta alta resistência, com valores iguais tanto na tração como na compressão. Possui uma curva tensão-deformação com trecho inicial elástico linear e trecho final elásto-plástico não linear. É melhor aproveitado quando utilizado em tração, pois em compressão pode apresentar problemas de flambagem das barras. Uma análise mais rigorosa destes efeitos exigem uma análise não-linear tanto física quanto geométrica.

Outro problema enfrentado na análise de concreto armado é a fissuração. Existem modelos que levam em conta a região fissurada e outros aproximam estas regiões por fissuras discretas. As análises usando-se estes modelos devem ser cuidadosas, pois podem apresentar resultados imprecisos.

Podemos ainda citar outros efeitos que acontecem na junção destes materiais, entre eles: a aderência; as fissuras, o engrenamento dos agregados e o confinamento. Todos eles provocam tensões e deformações diferenciadas.

Os trabalhos de experimentação e de modelagem numérica existem há muito tempo, mas ainda é grande o campo de investigação devido às melhorias na qualidade dos cimentos, à utilização de adições (sílica ativa) e superplastificantes que contribuíram para o surgimento do concreto de alto desempenho. Este material possui alta resistência à compressão com elevado módulo de elasticidade, o baixo fator água/cimento reduz a porosidade e aumenta a durabilidade. Devido as suas características é largamente utilizado em edifícios altos, pontes e viadutos. Entretanto, a ruptura brusca sem aviso é motivo de preocupação.

Normalmente nos escritórios de projeto estrutural as estruturas de concreto armado são analisadas em regime elástico-linear e os comportamentos não lineares do concreto e do aço são tratados separadamente. Devido à complexidade do comportamento desses dois materiais é necessária a análise experimental, cujos resultados servirão como base para as análises numéricas, as quais geram formulações empíricas e expressões que precisam ser ajustadas.

Apesar de todo o conhecimento, ainda não existe um modelo constitutivo capaz de levar em conta todos os comportamentos e fenômenos das estruturas de concreto armado $[2,3,4]$.

O comportamento mecânico do trabalho conjunto destes dois materiais é de difícil análise. Algumas formulações tratam de homogeneizar os dois materiais, modificando suas características físicas e relacionando-as com as taxas de armaduras em cada direção.

O modelo adotado neste trabalho considera os materiais de forma heterogênea considerando o comportamento do conjunto aço/concreto. Nas análises das estruturas em concreto armado serão levadas em conta as características físicas e a relação tensão-deformação segundo à lei constitutiva não linear de cada material [4,5].

As dificuldades de ensaio, instrumentação e custos, poderão ser consideravelmente reduzidas com a utilização de modelos computacionais, que geram respostas rápidas, práticas e precisas.

O objetivo principal deste trabalho é mostrar alguns resultados do desenvolvimento de um programa computacional, baseado no método dos elementos finitos, relatando-se a experiência dos autores no trato deste material [7]. 
O concreto será modelado por elementos finitos bi-dimensionais para estado plano de tensão, estado plano de deformação ou axissimétricos. $\mathrm{O}$ aço será modelado por elementos discretos de barras unidimensionais.

Um programa desta ordem exigirá um maior tempo na elaboração dos dados, maior capacidade de armazenamento e de processamento. Entretanto, as análises poderão ser realizadas em qualquer computador pessoal de ultima geração e a um custo final bem menor do que o de uma análise experimental.

Assim, pretende-se através da modelagem computacional investigar o comportamento conjunto do material aço-concreto de elementos estruturais de alto desempenho, aprofundando os conhecimentos dos mecanismos de colapso destes elementos. Nesta modelagem é possível obter resultados semelhantes ao experimental e proporcionar um dimensionamento seguro e racional.

\section{IMPLEMENTAÇÃO COMPUTACIONAL}

O programa computacional desenvolvido para estas análises foi baseado no método dos elementos finitos [5], com as seguintes características:

- Linguagem de programação FORTRAN;

- Elemento quadrático de oito nós para estados planos e axisssimetricos;

- Elemento uniaxial quadrático para modelagem das barras de aço.

- Integração com o programa GID [9] para pré e pós-processamento;

- Portabilidade de processamento para qualquer tipo de plataforma Windows ou Linux;

- Montagem e solução do sistema de equações pelo método de Gauss, usando uma técnica de solução frontal.

Critérios de ruptura dos materiais:

- Von-Mises;

- Tresca;

- Morh-Coulomb;

- Druger-Prager.

Método de Newton-Raphson modificado para a solução interativa de problemas não lineares.

O modelo admite perfeita aderência entre aço e concreto, ou seja, não há escorregamento entre os dois materiais.

Em alguns casos, a adoção de uma curva tensão-deformação bi-linear com um trecho elástico seguido de um endurecimento linear pode levar a resultados que não representem adequadamente o comportamento do elemento estrutural. Se a curva tensão-deformação do material for conhecida, isto poderá ser levado em conta na análise e este procedimento foi considerado na implementação computacional. Deve-se supor desta forma, que a curva-tensão deformação é formada por vários trechos lineares como mostra a figura 1. 


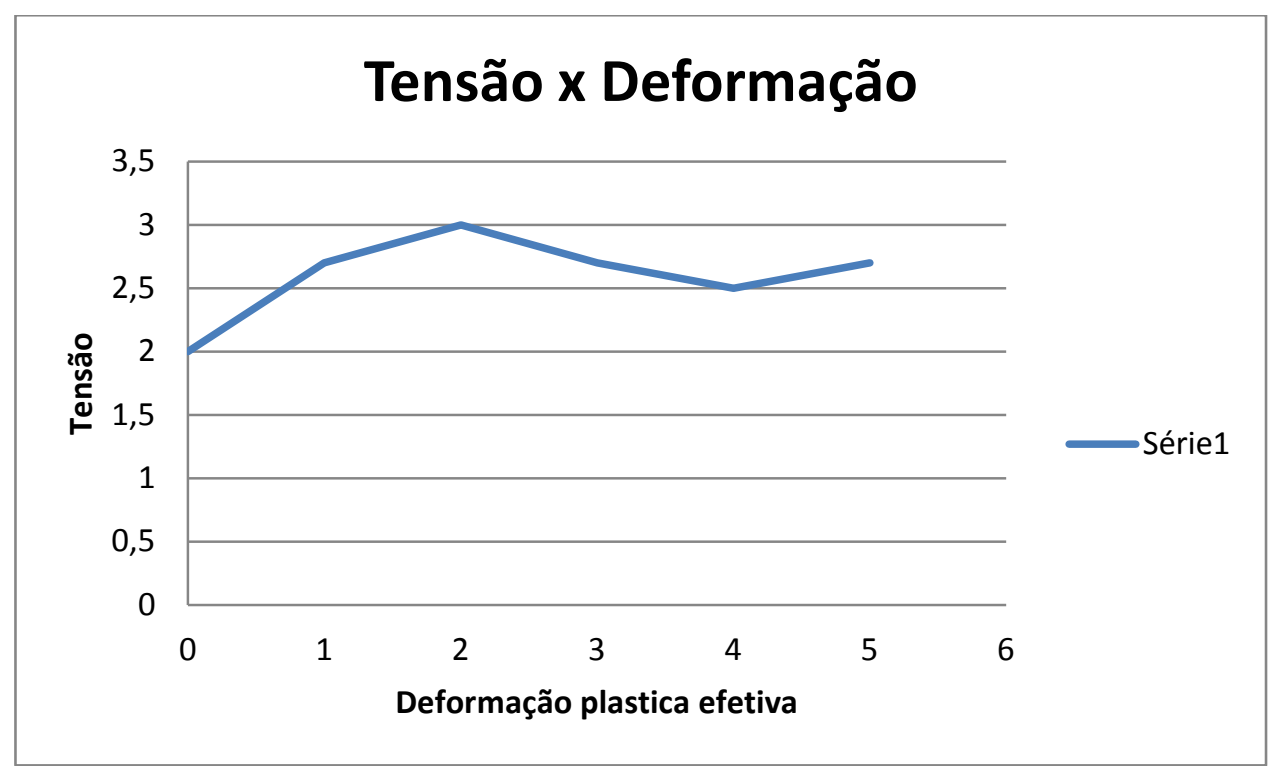

Figura 1 - Gráfico tensão - deformação dos trechos lineares.

Assim, a tensão de escoamento instantânea é dada por:

$$
\sigma_{y}=\sigma_{y}^{0}+S\left(\varepsilon_{p}\right)
$$

Onde: $\boldsymbol{\sigma}_{\boldsymbol{y}}{ }^{0}$ é a tensão de inicial de escoamento e $\boldsymbol{\varepsilon}_{\boldsymbol{p}}$ é o incremento de deformação plástica efetiva.

\section{MODELAGEM}

Com a finalidade de testar o programa desenvolvido, são realizadas análises numéricas em alguns elementos ensaiados por outros pesquisadores.

\subsection{Pilar á flexão composta}

O primeiro problema analisado é de um pilar submetido á flexão composta ensaiado por Vanderlei e Giongo [8].

O pilar tem seção retangular $150 \mathrm{~mm}$ x $300 \mathrm{~mm}$, armadura composta por $4 \phi 10 \mathrm{~mm}$ distribuída na face maior totalizando $8 \phi 10 \mathrm{~mm}$. Na modelagem não foram considerados os estribos.

As cargas nas bordas foram distribuídas e aplicadas de forma incremental, mantendo-se uma proporção constante entre a força de $(3000 \mathrm{kN})$ e o momento de $(60.000 \mathrm{kN} \mathrm{mm})$, ou seja, uma excentricidade de $20 \mathrm{~mm}$, atuando na direção de menor inércia. A figura 2 ilustra as cargas aplicadas nas extremidades do pilar, juntamente com a malha utilizada, aproveitandose da simetria. 

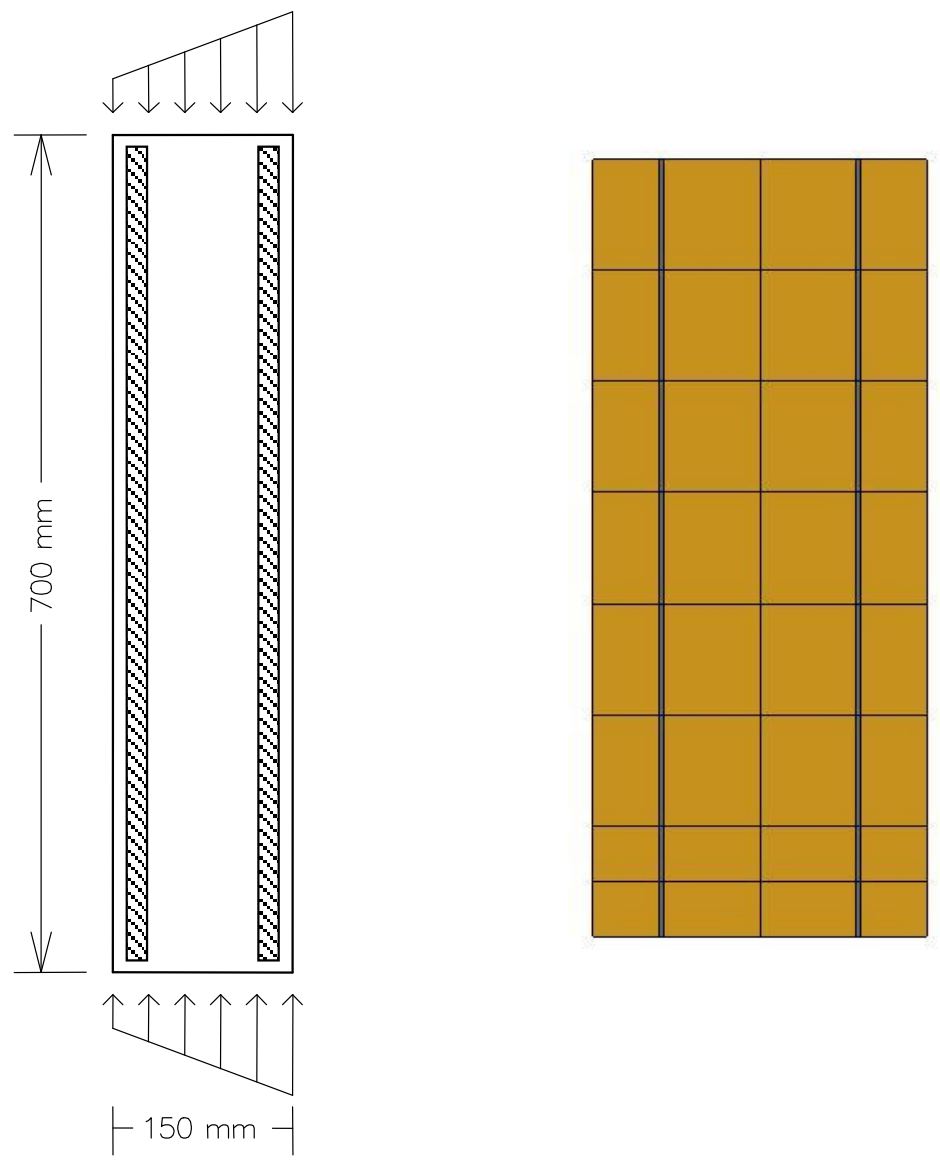

Figura 2 - Geometria, carga e malha utilizada para o pilar.

Dados do concreto de acordo com os resultados experimentais: $\mathrm{E}_{\mathrm{c}}=46000 \mathrm{MPa} ; \mathrm{f}_{\mathrm{c}}=$ 89,61 MPa; $v=0,2$ e $f_{t}=5,2 \mathrm{MPa}$. Com estes resultados e o estabelecido na NBR6118 [1] montou-se a curva tensão-deformação para o concreto, mostrada na figura 3 .

\begin{tabular}{|c|c|}
\hline Def.(\%o) & Tensão \\
\hline$-0,20$ & 0,00 \\
\hline$-0,10$ & $-4,75$ \\
\hline 0,00 & 0,0 \\
\hline 1,00 & 46,0 \\
\hline 1,76 & 80,7 \\
\hline 2,49 & 89,6 \\
\hline 3,50 & 89,6 \\
\hline
\end{tabular}

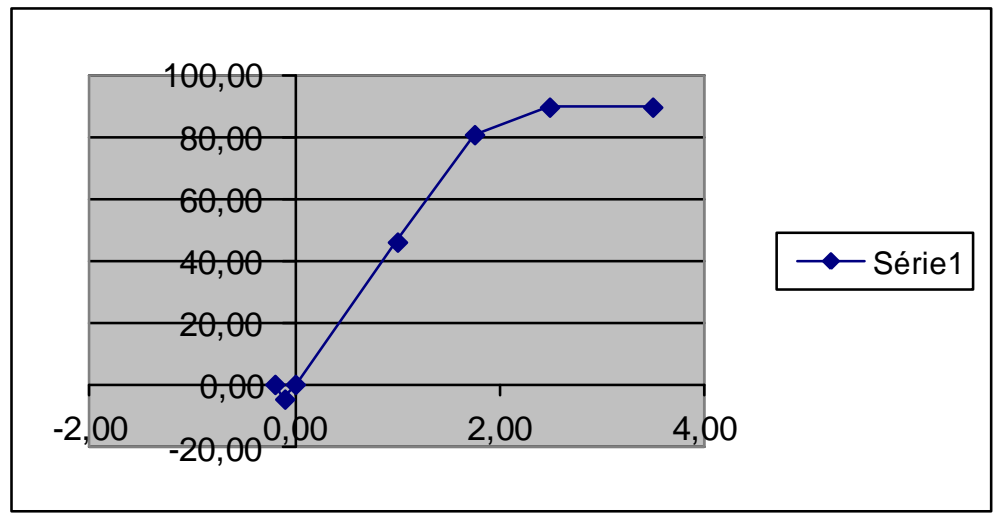

Figura 3 - Curva tensão-deformação para o concreto.

Dados do aço de acordo com os resultados experimentais: $\mathrm{E}=194060 \mathrm{MPa}$; fy $=623$ MPa e $v=0,3$. A tabela 1 mostra propriedades físicas do aço. 
Tabela 1 - Propriedades físicas do aço.

\begin{tabular}{|c|c|c|c|}
\hline & Def. (\%o) & Tensão (MPa) & Et (MPa) \\
\hline 1 & 0,00 & 0 & 0 \\
\hline 2 & 1,00 & 194,1 & 194060 \\
\hline 3 & 2,00 & 388,1 & 194060 \\
\hline 4 & 3,47 & 623,0 & 159782 \\
\hline 5 & 10,00 & 725,7 & 15727 \\
\hline
\end{tabular}

$\mathrm{Na}$ tabela 2 estão as deformações nas faces externas do concreto $\left(\varepsilon_{\mathrm{c} 1}\right.$ e $\left.\varepsilon_{\mathrm{c} 2}\right)$ e nas armaduras $\left(\varepsilon_{\mathrm{s} 1}\right.$ e $\left.\varepsilon_{\mathrm{s} 2}\right)$. De modo geral esta tabela mostra os resultados experimentais e da modelagem.

Tabela 2 - Resultados experimentais e da modelagem.

\begin{tabular}{|l|l|l|l|l|l|l|}
\hline Resultados & $\mathrm{F}_{\exp }(\mathrm{kN})$ & $\mathrm{M}_{\mathrm{exp}}(\mathrm{kNcm})$ & $\varepsilon_{\mathrm{c} 1}(\mathrm{o} / \mathrm{oo})$ & $\varepsilon_{\mathrm{c} 2}(\mathrm{o} / \mathrm{oo})$ & $\varepsilon_{\mathrm{s} 1}(\mathrm{o} / \mathrm{oo})$ & $\varepsilon_{\mathrm{s} 2}(\mathrm{o} / \mathrm{oo})$ \\
\hline $\begin{array}{l}\text { Carga Última } \\
\text { Experimental }\end{array}$ & 2902,2 & 5821,6 & 1,01 & 2,5 & 1,407 & 2,292 \\
$\begin{array}{l}80 \% \text { da Carga } \\
\text { Experimental }\end{array}$ & 2480 & 5560 & 0,8 & 1,9 & 1,068 & 1,673 \\
$\begin{array}{l}\text { Carga Última } \\
\text { Numérica }\end{array}$ & 2550 & 5100 & 0,187 & 2,43 & 0,596 & 1,78 \\
\hline Carga Numérica & 2400 & 4800 & 0,181 & 2,19 & 0,568 & 1,72 \\
\hline
\end{tabular}

Na figura 4 estão mostrados a deformada e as tensões normais para $2400 \mathrm{kN}$.
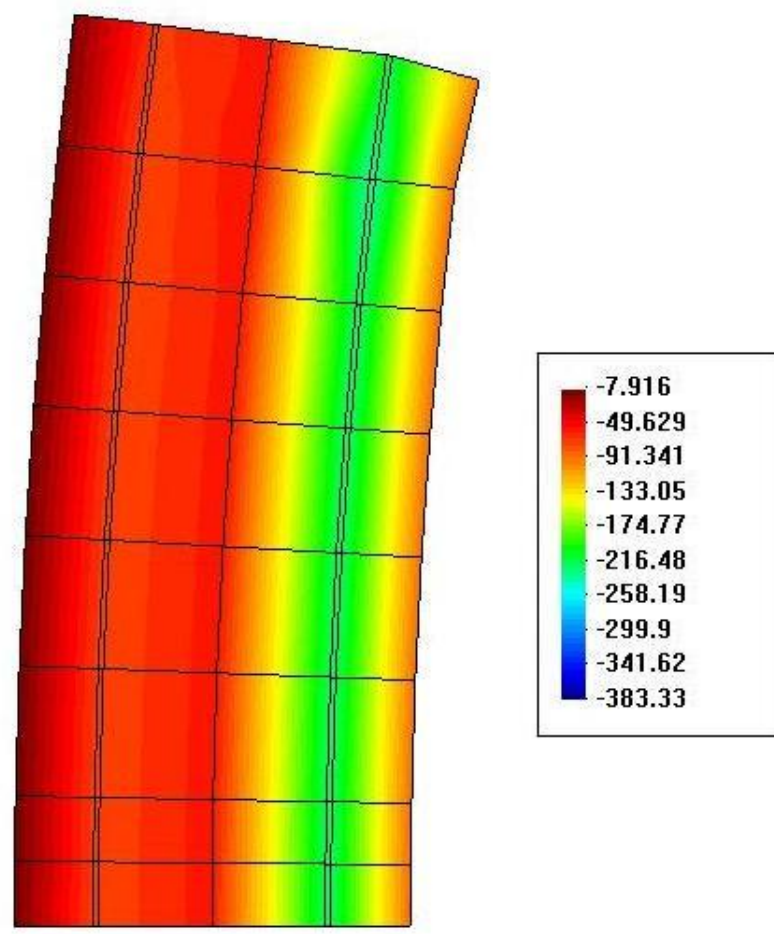

Figura 4 - Deformada e distribuição de tensões normais. 


\subsection{Viga á flexão}

O segundo problema analisado é uma viga sujeita à flexão simples, submetida a uma carga concentrada no meio do vão, que foi ensaiada experimentalmente por R. A. Souza [6], cujas características geométricas são mostradas na figura 5 .

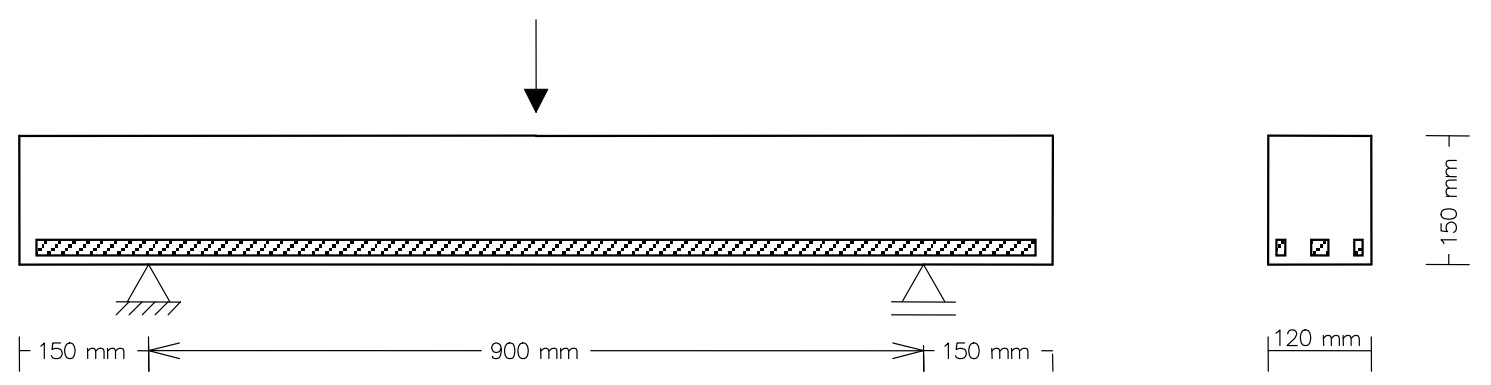

Figura 5 - Geometria da viga analisada.

A armadura longitudinal é formada por $2 \phi 4,2 \mathrm{~mm}$ e $1 \phi 5 \mathrm{~mm}$. Dados experimentais para o concreto: módulo de elasticidade tangente $=41649 \mathrm{MPa}$; Coeficiente de Poisson $=$ 0,19. O ângulo de atrito foi estimado em $60^{\circ}$.

Com base nos dados experimentais e expressão proposta pela NBR6118 [1], foi possível montar a curva tensão - deformação do concreto representada na figura 6. Considerou-se a compressão positiva e a tração negativa.

\begin{tabular}{|r|r|}
\hline Def. (\%o) & $\begin{array}{l}\text { Tensão } \\
\text { (MPa) }\end{array}$ \\
\hline$-0,00050$ & $-5,29$ \\
\hline$-0,00050$ & $-5,29$ \\
\hline$-0,00011$ & $-4,76$ \\
\hline 0 & 0,00 \\
\hline 0,001 & 54,15 \\
\hline 0,00125 & 62,05 \\
\hline 0,0015 & 67,69 \\
\hline 0,00175 & 71,07 \\
\hline 0,002 & 72,20 \\
\hline 0,0025 & 69,00 \\
\hline 0,0035 & 61,37 \\
\hline
\end{tabular}

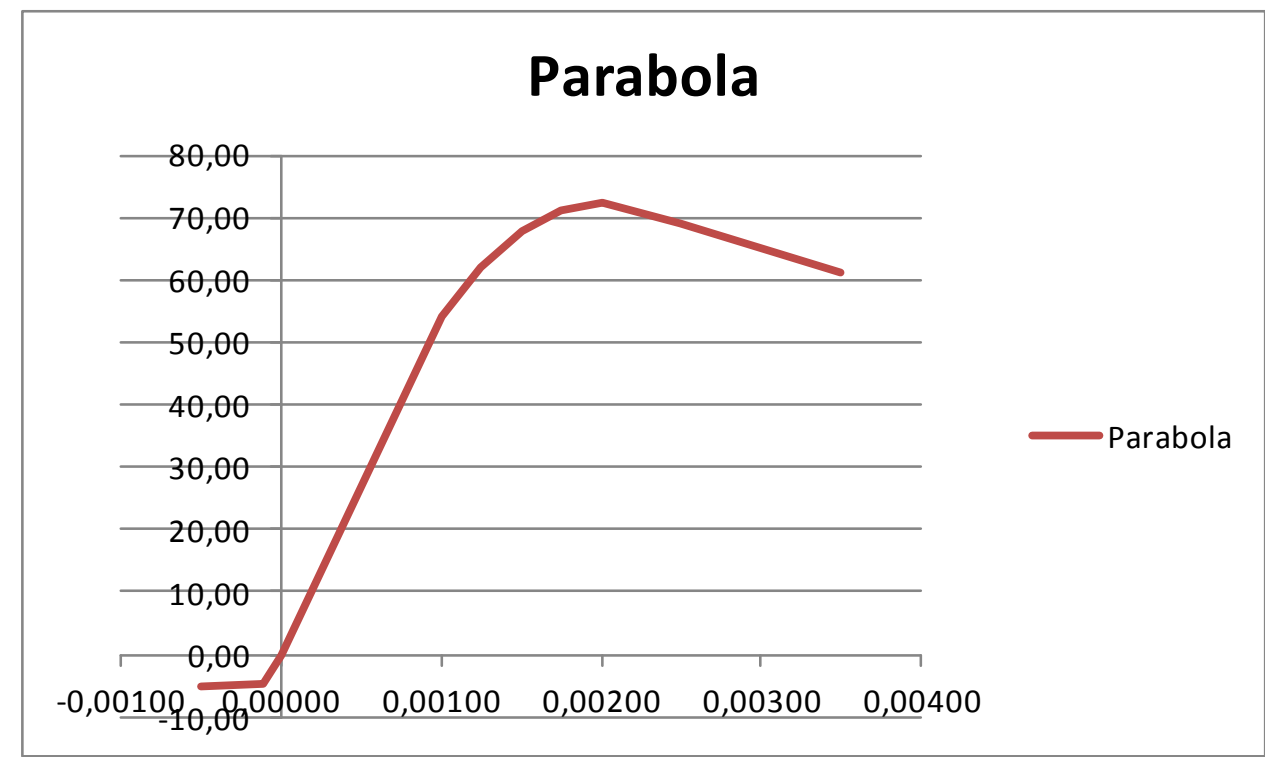

Figura 6 - Curva tensão - deformação do concreto.

Dados experimentais para o aço: módulo de elasticidade $=201900 \mathrm{MPa}$; Coeficiente de Poisson = 0,30; Tensão de escoamento 681,9 MPa; Máxima deformação plástica $10 \%$. Com base nestes dados adotou-se um diagrama bi-linear para o aço.

Aproveitando-se da simetria geométrica, a viga foi discretizada por 55 elementos quadráticos de 8 nós, num total de 198 nós. Na análise em EPT, utilizou-se como critério de rup- 
tura Morh-Coulomb para o concreto e critério de Tresca para o aço. A figura 7 mostra a malha junto com a deformada da viga. A tabela 3 mostra as flechas e a cargas obtidas no ensaio e através do programa. A figura 8 ilustra o gráfico carga - deslocamento.

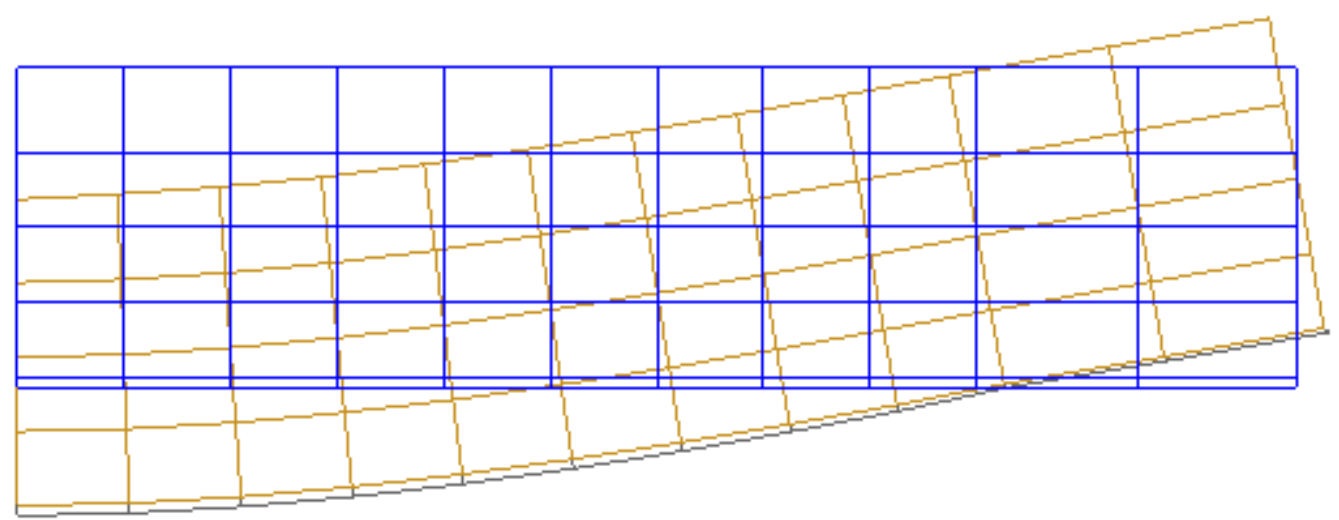

Figura 7 - Deformada e malha da viga.

Tabela 3 - Resultados das cargas e flechas da viga.

\begin{tabular}{|l|l|l|l|l|}
\hline & $\mathrm{P}_{\mathrm{cr}}(\mathrm{kN})$ & $\mathrm{P}_{\mathrm{u}}(\mathrm{kN})$ & $\delta_{\mathrm{cr}}(\mathrm{mm})$ & $\delta_{\mathrm{u}}(\mathrm{mm})$ \\
\hline Experimental & 13,06 & 21,09 & 0,32 & 2,93 \\
\hline Numéricos [6] & 16,77 & 19,86 & 0,22 & 0,99 \\
\hline Numéricos & 10,80 & 17,18 & 0,30 & 0,95 \\
\hline
\end{tabular}

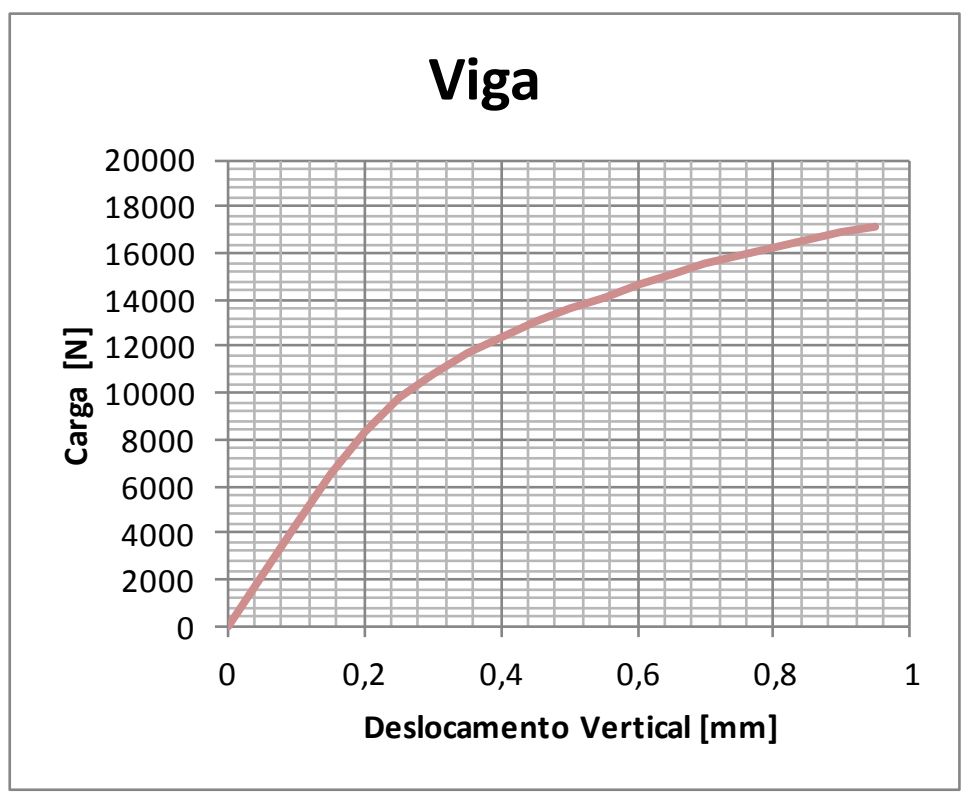

Figura 8 - Curva carga-deslocamento do ponto de aplicação da carga. 


\section{ANÁLISE DOS RESULTADOS}

\subsection{Pilar à flexão composta}

No modelo experimental a carga de ruptura foi de $2902,2 \mathrm{kN}$ e se deu por destacamento do cobrimento, enquanto na modelagem computacional a plastificação começou com $2100 \mathrm{kN}$ e atingiu a carga limite de $2550 \mathrm{kN}$, indicando ruptura do concreto na face mais comprimida.

Acredita-se que as deformações maiores obtidas experimentalmente foram devido a uma parcela de confinamento das extremidades, onde são aplicadas as cargas, que não acontece no modelo numérico. Outro efeito que se verifica é a interrupção da analise numérica quando a norma de energia cresce, enquanto na análise experimental há uma redução da carga com aumento de deslocamentos. Em regime plástico as deformações acontecem com mais velocidade não se conseguindo uma relação experimental precisa entre força e deslocamento. Isto causa alguma divergência entre a análise numérica e a experimental. Contudo, pode-se dizer que a analise numérica é mais conservadora tanto em relação à carga quanto aos deslocamentos, isto nos dá uma segurança em relação à carga ultima, mas nos fornece valores menores para os deslocamentos. Outro fato que colaborou na determinação de uma carga experimental maior é a presença de estribos, que provoca um confinamento do concreto, os quais não foram considerados na modelagem.

\subsection{Viga à flexão}

Mesmo utilizando uma análise incremental com controle de deslocamentos não se conseguiu detectar a redução da capacidade de carga prevista experimentalmente. Os resultados aqui obtidos foram bastante conservador tanto para carga ultima quanto para deslocamentos. Indicando uma carga de ruptura numérica da ordem de $20 \%$ menor do que a obtida experimental.

\section{CONCLUSÕES E SUGESTÕES PARA TRABALHOS FUTUROS}

Neste trabalho mostrou-se resultados de análises em elementos estruturais de alto desempenho com um programa computacional acadêmico e científico, especialmente desenvolvido para este fim. Este programa pode ser processado em qualquer computador pessoal a um custo final baixo, bem menor quando comparado com o de uma análise experimental. Vale ressaltar que, através deste programa é possível a análise, a verificação e a determinação de estados limites últimos de ruptura e de deformação de estruturas de concreto armado com relativa precisão.

Outro aspecto a ser destacado é o aumento do conhecimento em relação ao comportamento conjunto destes materiais, assim como dos mecanismos de ruptura destas estruturas. 
Acredita-se que a consideração dos estribos na modelagem aproximará os resultados numéricos e experimentais, já que os mesmo provocam confinamento no concreto.

Outra sugestão é introduzir elementos de contato entre o aço e o concreto, permitido assim o escorregamento para modelar o efeito de engrenamento dos agregados, controlar os deslocamentos e considerar critérios de fratura.

\section{AGRADECIMENTOS}

Os autores são gratos à Fundação Araucária, à Universidade Estadual de Londrina (UEL) e à Universidade Tecnológica Federal do Paraná - Campus Londrina (UTFPR), que apoiaram o desenvolvimento deste trabalho.

\section{REFERÊNCIAS}

[1] __ . NBR6118: 2003: Projeto de Estruturas de Concreto - Procedimento. Rio de Janeiro, 2003.

[2] Carpinteri, A. "Minimun Reiforcement in Concrete Member". Ed. Elsevier Applied Science, London and New York, 1999.

[3] Franca, Giuliana Furtado; Campos Filho, Américo. "Modelo de elementos finitos para análise de estruturas de concreto armado". 49. IBRACON, 2007.

[4] Hinton E.; Owen R. "Computational Modelling of Reinforced Concrete Structures". Ed. Pineridge Press, UK, 1986.

[5] Owen D.R.J.; Hinton E. “Finite Elements in Plasticity”. Ed. Pineridge Press, 1980.

[6] Souza, Rafael Alves de. "Análise do fraturamento em Estuturas de Concreto Utilizando Programas de Análise Estrutural”. Dissertação de Mestrado, UNICAMP, 2001.

[7] Souza, S.T.M et al. "Estudo Teórico Experimental de Dentes de Vigas Gerber Dimensionados Através de Modelos de Escoras e Tirantes Simples e Composto". 43․ Congresso Brasileiro do Concreto, Foz do Iguaçu, Brasil, 2001.

[8] Vanderlei R. D; Giongo J. S. “Análise Experimental de Pilares de Concreto Armado de Alta Resistência Sob Flexo Compressão Reta". Cadernos de Engenharia de Estruturas, São Carlos, n.21, p.81-105, 2003.

[9] GID - Programa para pré e pós processamento gráfico. http//:gid.cimne.upc.es. 